\title{
Abrupt withdrawal of atenolol in patients with severe angina: comparison with the effects of treatment
}

Sir,

The correspondence (1986;55:112-3) arising out of the paper by Dr Walker and colleagues ${ }^{1}$ prompts us to make the following comments. We agree with $\mathrm{Dr}$ Walker that the conclusions of the study should be confined to the specific clinical setting and should not be extended to encompass the view that it is never harmful to stop atenolol abruptly in patients with coronary artery disease.

Walker et al saw no serious coronary events in 20 patients with stable angina in the six days after atenolol was stopped. This is not surprising because few would regard the risk of serious consequences from abrupt $\beta$ blocker withdrawal as being high under these circumstances. They also noted no rebound in heart rate or blood pressure measured daily-this is also not surprising because these variables were recorded under unstressed conditions (which is why the earlier formal investigations into the phenomenon produced negative results). Furthermore, they saw no rebound in the consequences of treadmill exercise testing five days after atenolol was stopped-again this is not unexpected since these tests were probably on the late side and treadmill exercise is not the only form, and not necessarily the most potent form, of sympathetic stimulation to which patients may be exposed. These negative findings certainly do not demonstrate that the phenomenon of $\beta$ adrenergic hypersensitivity is absent after treatment with atenolol has been stopped, nor that it wouid be safe to ignore the possibility of this consequence in clinical practice.

The manifestation of increased $\beta$ adrenergic sensitivity as it gradually declines after the end of $\beta$ blocker treatment will depend upon the net level of $\beta$ adrenoceptor stimulation, and this in turn will depend upon the competition between sympathetic drive and the declining concentration of the $\beta$ blocking drug. Our data showed that the phenomenon is indeed present after atenolol is stopped; under the particular circumstances of our study (in which heart rate was measured when the patient was standing after sublingual glyceryl trinitrate) the rebound was significantly greater for the group as a whole only at four days and not at five days. It occurred 2-3 days after propranolol, oxprenolol, "slow release" oxprenolol, and acebutolol. ${ }^{23}$ Exercise, moreover, is only one way of increasing sympathetic drive, and the increased sympathetic drive with exercise is only one component cause of the increase in heart rate and myocardial energy requirements. Emotional stress, the reflex response to vasodilator drugs, or operation, can all cause very high $\beta$ adrenergic activity and it would not be wise to regard this as always being innocent.

M J Lewis, A $\mathrm{H}$ Henderson, Departments of Cardiology and Pharmacology, University of Wales College of Medicine, Cardiff CF4 4XN.

\section{References}

1 Walker PR, Marshall AJ, Farr S, Bauminger B, Walters G, Barritt DW. Abrupt withdrawal of atenolol in patients with severe angina: comparison with effects of treatment. Br Heart $\mathcal{F}$ 1985;53:276-82.

2 Ross PJ, Lewis MJ, Sheridan DJ, Henderson AH. Adrenergic hypersensitivity after beta-blocker withdrawal. Br Heart I 1981;45:637-42.

3 Singh H, Rimmer A, Lewis MJ, Henderson AH. Beta-adrenergic hypersensitivity after stopping oxprenolol: discrepant findings not attributable to methodology. Br f Clin Pharmacol 1983;16:722-4.

This letter was shown to Dr Walker, who replies as follows:

Sir,

I thank Dr Lewis and Dr Henderson for their comments and share their concern that the results of our study $^{1}$ should not be extrapolated too widelycertainly not towards the extreme view they fear might be adopted. Our own views remain those condensed in the final paragraph of our paper.

While I agree that, on previous evidence, the risk of serious consequences from abrupt atenolol withdrawal was very small (otherwise we should not have performed our study), we believed that more than just a few clinicians were still anxious about what to expect in patients with stable coronary artery disease. I disagree that for patients with severe angina a hospital admission for coronary arteriography and a discussion of its implications, two maximal exercise tests, and the other investigations described consti- 
tuted a period free of physical and emotional stress; however, as with previous similar studies ${ }^{23}$ no rebound effects or events were seen. As to whether exercise testing five days after atenolol withdrawal was too late to be influenced by adrenergic hypersensitivity, I refer Dr Lewis and Dr Henderson to their own paper in which they stated that "the peak rebound was reached at five (range four to seven) days after atenolol". 4 Inspection of their fig 2a shows that an exaggerated heart rate response to standing with vasodilatation-which was "significant" only on day four-also appears to have been in evidence as late as day six. I agree that the heart rate response during exercise is only partly determined by sympathetic drive, and we did not claim to have demonstrated absence of increased drive on day five; but rather that the threshold for myocardial ischaemia during physical activity did not appear to be influenced by it.

Concerning possible extrapolations from our results, we limited our speculation to the contention that, since abrupt atenolol withdrawal in patients with severe stable angina resulted in a gradual and uneventful disappearance of $\beta$ blockade, then in patients with mild or no symptoms a similarly uneventful outcome might be expected. Whereas to our knowledge this hope has not been disappointed in clinical practice, it seems fair to suggest that unduly wide extrapolations about the clinical importance of rebound hypersensitivity have been made by some, ${ }^{5}$ but certainly not all, ${ }^{4}$ workers who have succeeded in demonstrating this phenomenon in the laboratory. The rebound overshoot in heart rate response to standing with vasodilatation found after atenolol withdrawal by Ross et al appears to have averaged about 13 beats per minute. ${ }^{4}$ As we discussed, however, one consequence of atenolol withdrawal was that the heart rate at which myocardial ischaemia (angina and ST depression) became apparent during exercise was re-set upwards by as much as 35 (average 19) beats per minute.
Thus it does not follow that relatively small increases in heart rate (or sympathetic responsiveness or both) consequent upon $\beta$ blockade withdrawal will necessarily promote myocardial ischaemia, let alone provide the trigger for catastrophic coronary events. Speculation about the possible effect of vasodilators or operation during withdrawal seems unnecessary for most patients in whom withdrawal of treatment is regarded as appropriate.

As long as there are only a few firm data on its frequency and mechanisms the $\beta$ blockade withdrawal syndrome will doubtless continue to invoke controversy. As always, the clinician must make his own extrapolations from available data when considering the discontinuation of any particular $\beta$ blocker.

P R Walker, Department of Cardiology,

Bristol Royal Infirmary, Bristol BS2 8HW.

\section{References}

1 Walker PR, Marshall AJ, Farr S, Bauminger B, Walters G, Barritt DW. Abrupt withdrawal of atenolol in patients with severe angina: comparison with the effects of treatment. Br Heart $\mathcal{F}$ 1985; 53:276-82.

2 Myers MG, Freeman MR, Juma ZA, Wisenberg G. Propranolol withdrawal in angina pectoris: a prospective study. Am Heart F 1979;97:298-302.

3 Shiroff RA, Mathis J, Zelis R, et al. Propranolol rebound-a retrospective study. Am $\mathcal{F}$ Cardiol 1978; 41:778-80.

4 Ross PJ, Lewis MJ, Sheridan DJ, Henderson AH. Adrenergic hypersensitivity after beta-blockade withdrawal. Br Heart $\mathcal{F}$ 1981;45:637-42.

5 Nattel S, Rangno RE, Loon GV. Mechanism of propranolol withdrawal phenomena. Circulation 1979; 59:1158-64. 